\title{
Analysis of Information Technology Governance Using the COBIT 5 Framework (Case Study: E-Legal Drafting Legal Section of the Regional Secretariat of Salatiga City)
}

\section{Analisis Tata Kelola Teknologi Informasi Menggunakan Kerangka Kerja COBIT 5 (Studi Kasus: Bagian Hukum Perancangan E-Legal Sekretariat Daerah Kota Salatiga)}

\author{
Caecilia Ika Pramita Ady¹, Prihanto Ngesti Basuki², Augie David \\ Manuputty $^{3}$
}

\footnotetext{
${ }^{1}$ Information System Departement, Satya Wacana Christian University, Salatiga, Indonesia 2Information Technology Departement, Satya Wacana Christian University, Salatiga, Indonesia ${ }^{3}$ Information System Departement, Satya Wacana Christian University, Salatiga, Indonesia Email: 1682015088@student.uksw.edu,2ngesti@uksw.edu, ${ }^{3}$ augiemanuputty@gmail.com
}

\begin{abstract}
Information Technology (IT) governance is used to manage and optimize IT resources in supporting organizational goals. The Legal Section of the Regional Secretariat of Salatiga City as part of a government organization has built E-Legal Drafting information system to develop the functions of making regional legal products as well as the realization of e-government development in the legal field. The COBIT framework supports IT governance by providing work support to regulate IT alignment with the organization's business objectives. The results of this study are expected to show an overview of the implementation of IT governance in E-Legal Drafting information system from APO domain within the COBIT 5 framework, show the current system information level of capability and performance that is obtained from the measurement of capability levels, and also providing evaluation and recomendation based on the results of the gap analysis to help obtain the quality of information systems expected by the Legal Section of the Regional Secretariat of Salatiga City.
\end{abstract}

Keywords: COBIT 5, IT Governance, Information System, E-Legal Drafting

\section{PENDAHULUAN}

Kemajuan Teknologi Informasi (TI) dapat dimanfaatkan untuk mendukung jalannya proses bisnis dan menunjang peningkatan efektifitas dan efisiensi proses kinerja yang ada dalam suatu organisasi. Pemanfaatan TI saat ini sudah berkembang tidak hanya pada organisasi swasta saja, melainkan juga pada 
organisasi pemerintah dengan adanya pemerintahan elektronik (e-government), yaitu upaya penyelenggaraan pemerintahan berbasis elektronik untuk meningkatkan kualitas layanan publik menjadi lebih efektif dan efisien. Penerapan TI harus disesuaikan dengan kebutuhan dan proses bisnis organisasi sehingga dapat mendukung organisasi dalam mencapai tujuannya. Guna mencapai hal tersebut diperlukan suatu pengelolaan TI yang baik dan benar, sehingga keberadaan TI dirasakan kegunaannya oleh organisasi. Tata kelola TI (IT Governance) diartikan sebagai struktur kebijakan dan kumpulan proses organisasi yang bertujuan untuk memastikan kesesuaian penerapan TI dengan dukungannya terhadap pencapaian tujuan institusi.

Salah satu standar untuk mendukung tata kelola TI adalah framework COBIT (Control Objectives for Information and Related Technology). Pada penelitian ini digunakan COBIT versi 5 sebagai framework analisis. COBIT 5 merupakan standar komprehensif yang membantu perusahaan dalam mencapai tujuan dan menghasilkan nilai melalui tata kelola dan manajemen TI yang efektif. COBIT 5 menyediakan kerangka kerja IT Governance dan pengendalian tujuan (control objectives) yang rinci bagi manajemen, pemilik proses bisnis, pemakai dan auditor, sehingga nilai yang diberikan oleh TI dapat tercapai optimal dengan memperhatikan segala aspek tata kelola TI mulai dari sisi people, skills, competencies, services, infrastructure, dan applications yang merupakan bagian dari tata kelola TI [1].

Bagian Hukum Sekretariat Daerah (Setda) Kota Salatiga saat ini telah membangun sistem informasi E-Legal Drafting untuk melaksanakan fungsi pelayanan penyusunan produk hukum daerah sekaligus sebagai perwujudan pengembangan e-government di bidang hukum. Dalam pengelolaan sistem informasi ini, Bagian Hukum sebagai bagian dari Setda Kota Salatiga berkoordinasi dengan Dinas Komunikasi dan Informatika (Diskominfo) Kota Salatiga. Koordinasi ini dilakukan karena Setda Kota Salatiga tidak memiliki divisi IT tersendiri. Koordinasi seperti ini pun perlu dikelola dengan baik agar dapat memaksimalkan pemanfaatan TI untuk menunjang peningkatan efektifitas dan efisiensi proses kinerja pada organisasi pemerintah. Penelitian ini akan berfokus pada domain APO (Align, Plan, and Organise) yang sesuai diterapkan pada tata kelola TI yang baru akan dijalankan seperti sistem informasi E-Legal Drafting. Tujuan dari penelitian ini adalah untuk: (1) memperoleh gambaran implementasi tata kelola TI dengan framework. COBIT 5 domain APO pada sistem informasi ELegal Drafting Bagian Hukum Setda Kota Salatiga, (2) menunjukkan tingkat kemampuan dan performa sistem informasi saat ini yang diperoleh dari pengukuran capability level, serta (3) memberikan evaluasi dan rekomendasi berdasarkan hasil analisis gap untuk membantu pencapaian kualitas sistem informasi yang diharapkan oleh Bagian Hukum Setda Kota Salatiga. 


\section{METODOLOGI}

\subsection{Studi Pustaka}

Tata kelola TI (IT Governance) adalah kapasitas organisasi sebagai tanggung jawab direksi, manajemen eksekutif, dan manajemen teknologi informasi untuk mengendalikan rumusan dan implementasi strategi SI/TI untuk memastikan selarasnya sumber daya SI/TI dengan bisnis organisasi. Pengertian tata kelola TI ditekankan pada bagaimana organisasi memandang, mengelola dan mengoptimalkan sumber daya SI/TI yang dimilikinya dalam mendukung tujuan organisasi [2]. Tata kelola TI adalah struktur kebijakan atau prosedur dan kumpulan proses organisasi yang bertujuan untuk memastikan kesesuaian penerapan TI dengan dukungannya terhadap pencapaian tujuan institusi, dengan cara mengoptimalkan keuntungan dan kesempatan yang ditawarkan TI, mengendalikan penggunaan terhadap sumber daya TI dan mengelola resikoresiko terkait TI. Manfaat tata kelola TI diantaranya adalah untuk mengatur penggunaan TI dan memastikan kinerja TI sesuai dengan strategi bisnis perusahaan, performa layanan yang dihasilkan dari setiap proses TI yang diterapkan harus diukur secara reguler untuk memastikan output yang dihasilkan telah sesuai dengan yang diharapkan [3]. Pada dasarnya, tata kelola TI berkaitan dengan dua permasalahan utama: bahwa TI akan memberikan nilai terhadap bisnis yang didorong oleh penyelarasan TI dengan bisnis dan bahwa resiko yang terkait dengan TI akan ditangani dengan penentuan penanggung jawab permasalahan tersebut dalam perusahaan. dengan demikian, penyelarasan bisnis dan TI yang mengarahkan pada pemenuhan nilai bisnis adalah elemen kunci dari tata kelola TI [4].

COBIT (Control Objective for Information and Related Technology) merupakan sekumpulan dokumentasi dan panduan yang lebih berfokus terhadap tata kelola teknologi informasi serta manajemen teknologi informasi untuk mengimplementasikan IT Governance dengan kerangka kerja yang membantu auditor, manajemen, dan pengguna (user) untuk menjembatani pemisah (gap) antara risiko bisnis, kebutuhan kendali, dan permasalahan-permasalahan teknis dalam penerapan teknologi informasi dalam organisasi. COBIT dikembangkan oleh IT Governance Institute (ITGI) yang merupakan bagian dari Information Systems Audit and Control Association (ISACA) [3]. COBIT mendukung tata kelola TI dengan menyediakan kerangka kerja untuk mengatur keselarasan TI dengan bisnis. Selain itu, kerangka kerja juga memastikan bahwa TI memungkinkan bisnis, memaksimalkan keuntungan, resiko TI dikelola secara tepat, dan sumber daya TI digunakan secara bertanggung jawab [1]. Aktivitas teknologi informasi pada COBIT 5 memiliki dua area kerja utama yang dipisahkan antara management (manajemen) dan governance (tata kelola): (a) Governance, terdiri atas lima domain dalam proses Evaluate, Direct, and Monitor (EDM), (b) Management, terdiri atas empat domain utama yang bertanggung jawab pada area Plan, Build, Run, and Monitor (PBRM) dan menyediakan cakupan end-to-end TI. Domain-domain pada 
Vol. 1, No. 2, September 2019

p-ISSN: 2656-5935 http://journal-isi.org/index.php/isi

e-ISSN: 2656-4882

area ini adalah evolusi dari domain COBIT 4.1 dan process structure dengan perkembangan yang dapat mencakup area yang lebih luas, yaitu Align, Plan, and Organise (APO), Build, Acquire, and Implement (BAI), Deliver, Service, and Support (DSS), dan Monitor,Evaluate, and Assess (MEA) [5]. Gambar 1 menunjukkan

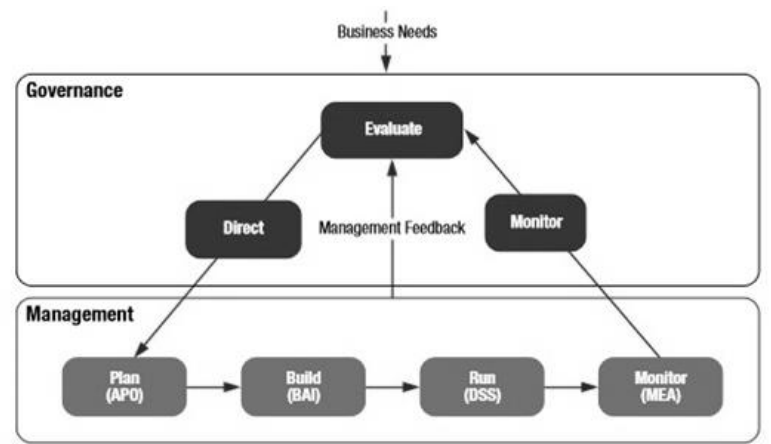

pemisahan area kerja pada COBIT 5.

Gambar 1. Pemisahan Area Kerja pada COBIT 5 [5]

COBIT 5 menerangkan bahwa RACI chart adalah matriks untuk seluruh aktivitas atau otorisasi keputusan yang harus diambil dalam suatu organisasi yang dikaitkan dengan seluruh pihak atau posisi yang terlibat [2]. Diagram RACI adalah bagian dari Responsibility Assignment Matrix (RAM), yaitu bentuk pemetaan antara sumber daya dengan aktivitas dalam setiap prosedur. RACI merupakan singkatan dari: (a) R (Responsible), berarti bahwa bagian tersebut merupakan pihak pelaksana yang harus bertanggung jawab melaksanakan dan menyelesaikan aktivitas yang menjadi tanggung jawabnya, (b) A (Accountable), berarti bahwa bagian tersebut merupakan pihak yang harus mengarahkan jalannya pelaksanaan aktivitas, (c) C (Consulted), berarti bahwa bagian tersebut merupakan pihak yang akan menjadi tempat konsultasi selama pelaksanaan aktivitas, dan (d) I (Informed), berarti bahwa bagian tersebut merupakan pihak yang diberikan infromasi mengenai pelaksanaan aktivitas [1].

ISO/IEC 15505 mendefinisikan pengukuran untuk penilaian kemampuan proses dari framework COBIT. Process capability (kapabilitas proses) merupakan karakteristik dari kemampuan sebuah proses untuk mencapai tujuan bisnis saat ini ataupun saat mendatang. Pengukuran capability level dilakukan untuk memahami kematangan proses yang dilakukan berdasarkan domain yang ada pada COBIT 5 untuk mendefinisikan tingkat kematangan dan menetapkan kesenjangan yang didapatkan antara tingkat kematangan saat ini (as-is) dengan tingkat kematangan yang diharapkan (to-be) [6]. Kapabilitas proses didefinisikan pada enam level poin dari 0 sampai 5, yang mempresentasikan peningkatan capability dari proses yang diimplementasikan [1]. Penjelasan dari tiap level tersebut adalah sebagai berikut: (a) Level 0 (Incomplete process), pada level ini proses 
tidak diimplementasikan atau gagal mencapai tujuan prosesnya, ada sedikit atau tidak ada bukti pencapaian sistematis dari tujuan proses, (b) Level 1 (Performed process), pada level ini proses yang diimplementasikan sudah mencapai tujuan prosesnya, (c) Level 2 (Managed process), proses yang dideskripsikan sebelumnya sudah diimplementasikan dengan proses yang dikelola (direncanakan, dipantau dan disesuaikan) dan hasil kerjanya sudah ditetapkan, dikendalikan dan dirawat dengan tepat. (d) Level 3 (Established process), proses yang dideskripsikan sebelumnya sudah diimplementasikan menggunakan proses yang dianggap akan mampu mencapai hasil prosesnya, (e) Level 4 (Predictable process), proses yang dideskripsikan sudah beroperasi dalam batas yang ditentukan untuk mencapai hasil prosesnya, (f) Level 5 (Optimizing process), proses yang dideskripsikan sebelumnya ditingkatkan secara terus menerus untuk memenuhi tujuan organisasi saat ini dan yang diproyeksikan di masa mendatang [7].

Setiap proses dinilai menggunakan skala peringkat standar yang ditentukan dalam standar ISO / IEC 15504. Peringkat ini terdiri dari: (a) N (Not achieved), ada sedikit atau tidak ada bukti pencapaian dari atribut yang didefinisikan dalam proses yang dinilai, (b) P (Partially achieved), ada beberapa bukti pendekatan dan pencapaian dari atribut yang didefinisikan dalam proses yang dinilai, (c) L (Largely achieved), ada bukti pendekatan sistematis dan pencapaian signifikan dari atribut yang didefinisikan dalam proses yang dinilai, (d) F (Fully achieved), ada bukti pendekatan yang lengkap dan sistematis, pencapaian penuh dari atribut yang didefinisikan dalam proses yang dinilai, dan tidak ada kelemahan signifikan terkait dengan atribut ini ada dalam proses yang dinilai [7]. Ada suatu kebutuhan untuk memastikan tingkat interpretasi yang konsisten ketika memutuskan peringkat mana yang akan ditetapkan. Tabel 1 menunjukkan nilai capaian masing-masing rating scale dalam persentase.

Tabel 1. Nilai Rating Scale dalam Persentase [7]

\begin{tabular}{ccc}
\hline Abbreviation & Description & $\mathbf{\%}$ Achieved \\
\hline N & Not achieved & 0 to $15 \%$ achievement \\
\hline P & Partially achieved & $>15 \%$ to $50 \%$ achievement \\
\hline L & Largely achieved & $>50 \%$ to $85 \%$ achievement \\
\hline F & Fully achieved & $>85 \%$ to $100 \%$ achievement \\
\hline
\end{tabular}

\subsection{Tahapan Penelitian}

Penelitian ini menggunakan metode penelitian deskriptif kualitatif dimana hasil pengumpulan data dideskripsikan berdasarkan perspektif narasumber dengan memperhatikan kondisi riil di lapangan [2]. Gambar 2 menunjukkan tahapan penelitian ini. Tahap pertama dalam penelitian ini adalah mempelajari gambaran organisasi secara umum yaitu mengenai visi dan misi dari Bagian Hukum sebagai bagian dari Setda Kota Salatiga dan mempelajari profil sistem informasi E-Legal 
Vol. 1, No. 2, September 2019

p-ISSN: 2656-5935 http://journal-isi.org/index.php/isi e-ISSN: 2656-4882

Drafting beserta proses-proses yang ada didalamnya. Tahap berikutnya, melakukan studi pustaka dengan mencari dan mempelajari buku serta jurnal mengenai COBIT dan analisis tata kelola TI untuk mendapatkan lebih banyak pemahaman mengenai topik penelitian. Selanjutnya dilakukan pemetaan enterprise goal dengan IT-related goal untuk menyelaraskan visi misi organisasi dengan proses yang ada pada COBIT 5. Setelah didapatkan hasil pemetaan, selanjutnya dilakukan pengumpulan data yang diperlukan dengan cara observasi, pemberian kuesioner dan wawancara dengan fokus utama pada domain APO (Align, Plan, and Organise), serta pencarian dokumen yang terkait dengan sistem informasi $E$ Legal Drafting. Pengumpulan data dilakukan dengan melakukan observasi langsung di lapangan, membagikan kuesioner dan melakukan wawancara dengan narasumber yang terdapat dalam RACI chart yang ditunjukkan pada Tabel 2.

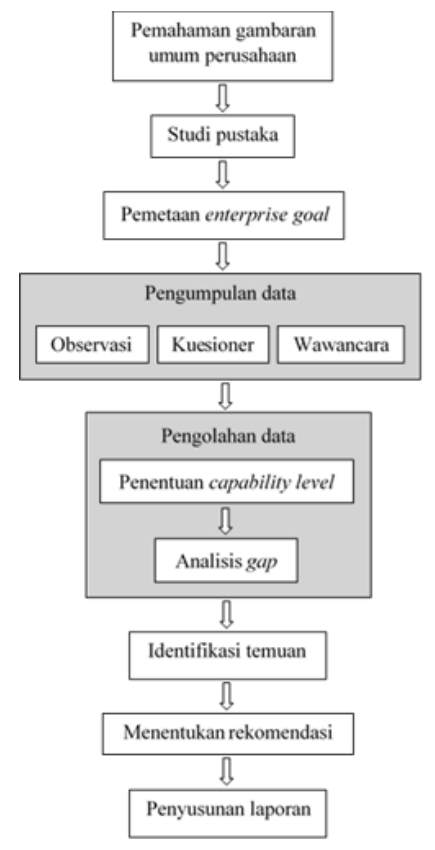

Gambar 2. Tahapan Penelitian (diolah oleh Penulis)

Tabel 2. RACI Chart

\begin{tabular}{cl}
\hline RACI & \multicolumn{1}{c}{ Jabatan } \\
\hline R & Kepala Sub Bagian Fasilitasi Produk Hukum Daerah \\
\hline A & Kepala Bagian Hukum Setda Kota Salatiga \\
\hline C & Pranata Komputer Ahli Muda Dinas Kominfo \\
\hline I & Staff Sub Bagian Fasilitasi Produk Hukum Daerah \\
\hline
\end{tabular}


Vol. 1, No. 2, September 2019

p-ISSN: 2656-5935 http://journal-isi.org/index.php/isi e-ISSN: 2656-4882

Tahap selanjutnya adalah melakukan pengolahan data dari hasil observasi, kuesioner dan wawancara terkait proses-proses yang ada dalam domain APO. Proses pengolahan data ini dilakukan dengan penentuan capability level yang akan menggambarkan tingkat kematangan sistem informasi saat ini. Setelah didapatkan capability level, kemudian dilakukan analisis gap untuk mengetahui kesenjangan yang didapatkan antara tingkat kematangan saat ini dengan tingkat kematangan yang diharapkan oleh organisasi. Selanjutnya adalah melakukan identifikasi temuan yang didapatkan dari hasil pengolahan data. Tahap berikutnya adalah menentukan rekomendasi dari hasil analisis temuan sebagai bahan untuk melakukan evaluasi dari proses yang belum maksimal. Tahap terakhir dalam penelitian ini adalah melakukan penyusunan laporan yang berisi hasil identifikasi temuan beserta rekomendasi yang kemudian akan diserahkan ke Bagian Hukum Setda Kota Salatiga.

\section{HASIL DAN PEMBAHASAN}

Analisis tata kelola TI pada Bagian Hukum Setda Kota Salatiga dimulai dengan pemetaan visi misi organisasi ke dalam COBIT 5 Enterprise Goal, dilanjutkan dengan memetakan pada IT-related Goal kemudian dipetakan lagi ke dalam COBIT 5 Process, sehingga didapatkan domain beserta proses-prosesnya yang akan digunakan untuk melakukan analisis.

Visi misi Setda Kota Salatiga tertuang dalam Rencana Strategis (Renstra) Sekretariat Daerah Kota Salatiga Tahun 2011-2016. Pemetaan visi misi terhadap COBIT 5 Enterprise Goal ditunjukkan pada Tabel 3.

Tabel 3. Pemetaan visi misi ke dalam COBIT 5 Enterprise Goal [5]

\begin{tabular}{|c|c|c|c|c|}
\hline \multirow[b]{2}{*}{$\begin{array}{c}\text { BSC } \\
\text { Dimension }\end{array}$} & \multirow[b]{2}{*}{ Enterprise Goal } & \multicolumn{3}{|c|}{ Relation to Governance Objectives } \\
\hline & & $\begin{array}{c}\text { Benefits } \\
\text { Realisation }\end{array}$ & $\begin{array}{c}\text { Risk } \\
\text { Optimisat } \\
\text { ion }\end{array}$ & $\begin{array}{c}\text { Resource } \\
\text { Optimisat } \\
\text { ion }\end{array}$ \\
\hline \multirow[t]{5}{*}{ Financial } & 1. Stakeholder value of business investments & $\mathrm{P}$ & & $\mathrm{S}$ \\
\hline & 2. Portfolio of competitive products and services & $\mathrm{P}$ & $\mathrm{P}$ & S \\
\hline & 3. Managed business risk (safeguarding of assets) & & $\mathrm{P}$ & S \\
\hline & 4. Compliance with external laws and regulations & & $\mathrm{P}$ & \\
\hline & 5. Financial transparency & $\mathrm{P}$ & S & $\mathrm{S}$ \\
\hline \multirow[t]{5}{*}{ Customer } & 6. Customer-oriented service culture & $\overline{\mathrm{P}}$ & & S \\
\hline & 7. Business service continuity and availability & & $\mathrm{P}$ & \\
\hline & $\begin{array}{l}\text { 8. Agile responses to a changing business } \\
\text { environment }\end{array}$ & $\mathrm{P}$ & & S \\
\hline & 9. Information-based strategic decision making & $\mathrm{P}$ & $\mathrm{P}$ & $\mathrm{P}$ \\
\hline & 10. Optimisation of service delivery costs & $\mathrm{P}$ & & $\mathrm{P}$ \\
\hline \multirow[t]{5}{*}{ Internal } & 11. Optimisation of business process functionality & $\mathrm{P}$ & & $\mathrm{P}$ \\
\hline & 12. Optimisation of business process costs & $\overline{\mathrm{P}}$ & & $\overline{\mathrm{P}}$ \\
\hline & 13. Managed business change programmes & $\mathrm{P}$ & $\mathrm{P}$ & $\mathrm{S}$ \\
\hline & 14. Operational and staff productivity & $\mathrm{P}$ & & $\mathrm{P}$ \\
\hline & 15. Compliance with internal policies & & $\mathrm{P}$ & \\
\hline Learning and & 16. Skilled and motivated people & $\mathrm{S}$ & $\mathrm{P}$ & $\mathrm{P}$ \\
\hline Growth & 17. Product and business innovation culture & $\mathrm{P}$ & & \\
\hline
\end{tabular}


Vol. 1, No. 2, September 2019

p-ISSN: 2656-5935 http://journal-isi.org/index.php/isi

e-ISSN: $2656-4882$

Dalam pemetaan visi misi, Balanced Scorecard (BSC) Dimension digunakan untuk mengelompokkan Enterprise Goal ke dalam empat perspektif, yaitu Financial (Keuangan), Customer (Pelanggan), Internal, dan Learning and Growth (Pembelajaran dan Pertumbuhan). Pada perspektif financial, organisasi menjalankan transparansi keuangan dimana organisasi memberikan informasi keuangan yang terbuka dan jujur sebagai pertanggungjawaban pemerintah dalam pengelolaan sumber daya dan ketaatannya pada peraturan perundang- undangan. Pada perspektif customer, keberlanjutan dan ketersediaan pelayanan bisnis menjadi tujuan organisasi untuk meningkatkan kinerja dan mutu pelayanan dalam lingkup pemerintahan daerah. Pada perspektif internal, organisasi menjalankan pengoptimalisasian dari fungsionalitas proses bisnis dimana fungsi pelayanan diharapkan untuk mampu berjalan dengan mudah, efisien tenaga dan waktu dalam pelaksanaannya. Kemudian pada perspektif learning and growth, organisasi mengupayakan kualitas sumber daya manusia yang kompeten dalam bidangnya dan memiliki motivasi kerja yang baik sehingga akan mampu mendukung tercapainya tujuan organisasi secara maksimal. Selanjutnya dilakukan pemetaan Enterprise Goal ke dalam ITrelated Goal, seperti yang ditunjukkan pada Gambar 3. Pemetaan ini dinyatakan dengan menggunakan skala 'P' (Primary) ketika ada hubungan yang penting, dan skala 'S' (Secondary) ketika masih ada hubungan yang kuat, tetapi kurang penting dan merupakan dukungan sekunder.

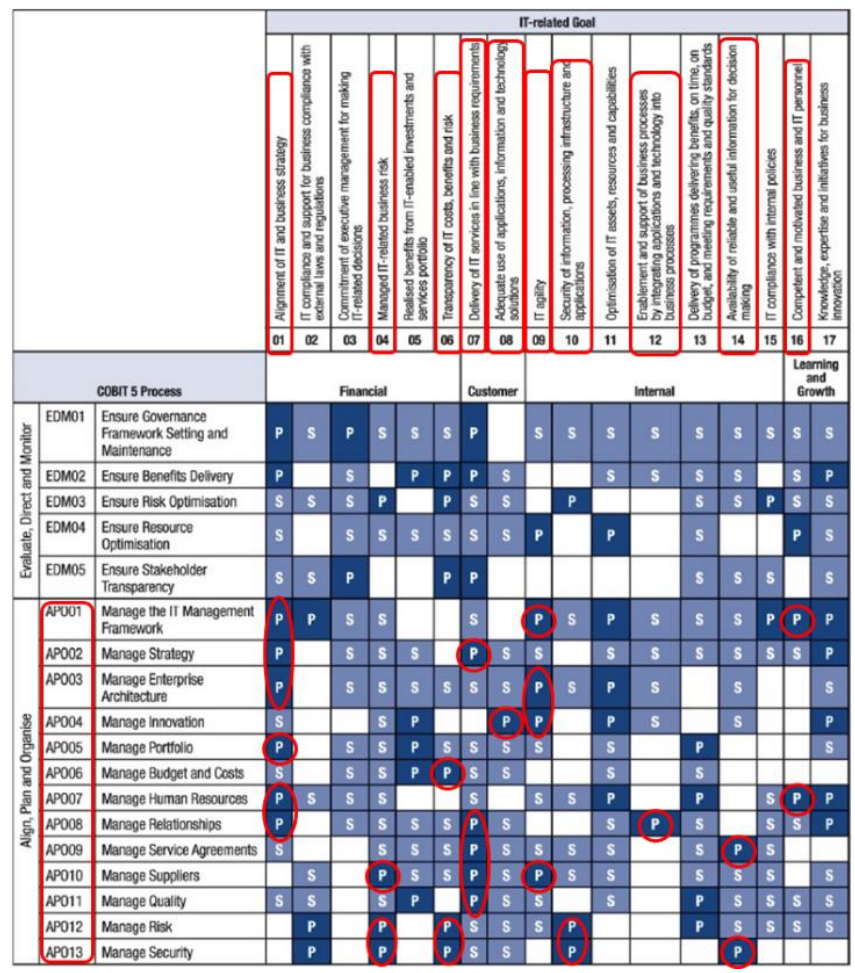

Gambar 3. Pemetaan Enterprise Goal ke dalam IT-related Goal [5] 
Vol. 1, No. 2, September 2019

p-ISSN: 2656-5935 http://journal-isi.org/index.php/isi

e-ISSN: 2656-4882

Proses selanjutnya adalah memetakan IT-related Goal ke dalam COBIT 5 Process. Sama dengan pemetaan sebelumnya, terdapat skala 'P' (Primary) yang menunjukkan hubungan penting, dan skala 'S' (Secondary) yang menunjukkan dukungan sekunder. Pemetaan ditunjukkan pada Gambar 4.

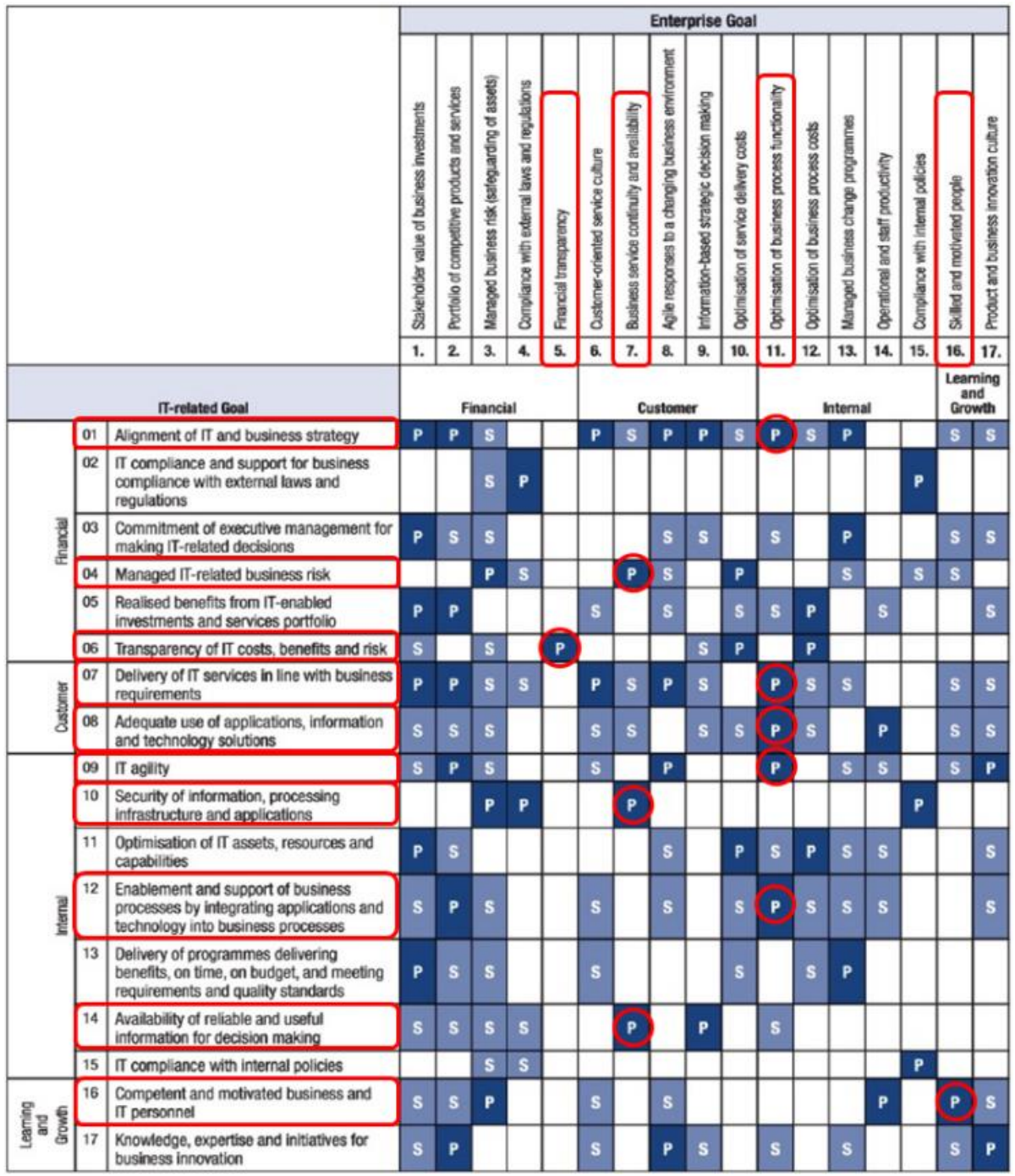

Gambar 4. Pemetaan IT-related Goal ke dalam COBIT 5 Process [5]

Berdasarkan hasil pemetaan COBIT 5 Process dan menyesuaikan fokus penelitian ini pada domian APO, didapatkan keseluruhan domain APO (APO01, APO02, APO03, APO04, APO05, APO06, APO07, APO08, APO09, APO10, APO11, APO12, APO13) yang akan digunakan sebagai acuan dalam proses analisis. 
Vol. 1, No. 2, September 2019

p-ISSN: 2656-5935 http://journal-isi.org/index.php/is

e-ISSN: 2656-4882

Berdasarkan hasil observasi, wawancara dan pengisian kuesioner oleh narasumber, maka diperoleh level hasil pengukuran kondisi saat ini dan rating scale dari tiap proses sub domain. Kemudian berdasarkan hasil wawancara dengan Kepala Sub Bagian Fasilitasi Produk Hukum Daerah, disampaikan bahwa target capability level yang diharapkan dalam waktu dekat adalah pada level 4. Tabel 4 menunjukkan pengukuran capability level dan gap pada domain APO.

Tabel 4. Pengukuran dan Identifikasi Capability Level dan Gap Domain APO

\begin{tabular}{clcccc}
\hline $\begin{array}{c}\text { Sub } \\
\text { Domain }\end{array}$ & \multicolumn{1}{c}{ Proses } & $\begin{array}{c}\text { Capability } \\
\text { Level }\end{array}$ & Persentase & $\begin{array}{c}\text { Rating } \\
\text { Scale }\end{array}$ & Gap \\
\hline APO01 & $\begin{array}{l}\text { Define the Management } \\
\text { Framework for IT }\end{array}$ & 2,44 & $81 \%$ & L & 1,56 \\
\hline APO02 & Define Strategy & 2,50 & $83 \%$ & L & 1,50 \\
\hline APO03 & $\begin{array}{l}\text { Manage Enterprise } \\
\text { Architecture }\end{array}$ & 2,88 & $96 \%$ & F & 1,12 \\
\hline APO04 & Manage Innovation & 2,66 & $89 \%$ & F & 1,34 \\
\hline APO05 & Manage Portfolio & 2,83 & $94 \%$ & F & 1,17 \\
\hline APO06 & Manage Budget and Costs & 2,75 & $92 \%$ & F & 1,25 \\
\hline APO07 & Manage Human Resources & 2,17 & $72 \%$ & L & 1,83 \\
\hline APO08 & Manage Relationships & 2,88 & $96 \%$ & F & 1,12 \\
\hline APO09 & Manage Service Agreements & 2,33 & $78 \%$ & L & 1,67 \\
\hline APO10 & Manage Suppliers & 2,80 & $93 \%$ & F & 1,20 \\
\hline APO11 & Manage Quality & 2,88 & $96 \%$ & F & 1,12 \\
\hline APO12 & Manage Risk & 2,50 & $83 \%$ & L & 1,50 \\
\hline APO13 & Manage Security & 2,50 & $83 \%$ & L & 1,50 \\
\hline & Total & 34,12 & & & \\
\hline & Rata-rata & 2,62 & $87 \%$ & F & 1,38 \\
\hline
\end{tabular}

Berdasarkan persentase dari hasil pengukuran tiap proses sub domain, diperoleh dua kategori rating scale yang menggambarkan pencapaian capability level saat ini, yaitu L (Largely achieved) untuk pencapaian $>50 \%$ hingga 85\% dan F (Fully achieved) untuk pencapaian $>85 \%$ hingga 100\%. Dari tabel di atas juga diperoleh perhitungan rata-rata capability level tata kelola sistem informasi E-Legal Drafting Bagian Hukum Setda Kota Salatiga adalah 2,62 yang berada pada rating scale F (Fully achieved) dengan persentse $87 \%$ dan memiliki gap sebesar 1,38 untuk mencapai target capability yang diharapkan yaitu pada level 4. Adapun hasil pengukuran gap antara capability level yang diharapkan dengan capability level saat ini dari tiap proses sub domain dapat lebih jelas dilihat pada Gambar 5. 
Vol. 1, No. 2, September 2019

p-ISSN: 2656-5935 http://journal-isi.org/index.php/isi e-ISSN: 2656-4882

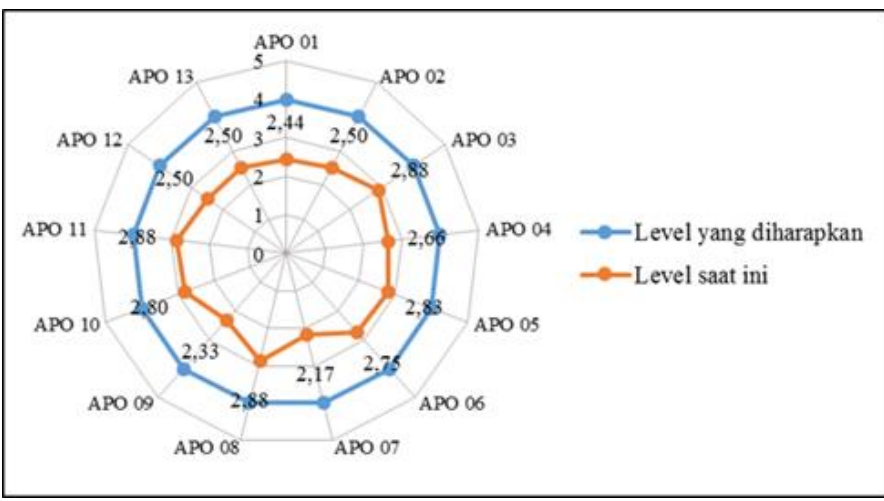

Gambar 5. Grafik Pengukuran Gap Capability Level Tiap Proses Sub Domain APO

Sub domain APO 01, define the management framework for IT, berada pada rating scale Largely achieved (L) dengan persentase $81 \%$ yang menunjukkan pencapaian signifikan dari proses-proses yang dijalankan: (1) sudah merencanakan proses maintenance (pemeliharaan) dari sistem informasi yang akan digunakan, (2) sudah menentukan dan membentuk struktur organisasi untuk melaksanakan pembinaan dan pengawasan terhadap sistem informasi yang akan digunakan, tetapi masih ada anggota yang belum berperan secara maksimal, (3) sudah membuat prosedur untuk menjaga kepatuhan pengguna (user) dalam mengikuti alur kerja sistem, tetapi konsekuensi pelanggaran prosedur tersebut belum dijalankan dengan tegas.

Sub domain APO 02, define strategy, berada pada rating scale Largely achieved (L) dengan persentase $83 \%$ yang menunjukkan pencapaian signifikan dari proses penentuan target dan kemampuan TI yang diharapkan dengan cara memetakan alur proses kerja manual yang memerlukan pengoptimalan melalui sistem informasi yang akan dibangun.

Sub domain APO 03, manage enterprise architecture, berada pada rating scale Fully achieved (F) dengan persentase 96\%. Hasil ini menunjukkan pencapaian penuh dari proses pemetaan arsitektur atau gambaran alur proses kerja yang akan dioptimalkan dengan penggunaan sistem informasi E-Legal Drafting untuk memaksimalkan fungsi TI dan memastikan tersedianya sumber daya yang baik untuk menjalankan proses ini.

Sub domain APO 04, manage innovation, berada pada rating scale Fully achieved (F) dengan persentase $89 \%$. Hasil ini menunjukkan pencapaian penuh dari terciptanya lingkungan organisasi yang kondusif untuk menampung inovasiinovasi yang ada.

Sub domain APO 05, manage portofolio, berada pada rating scale Fully achieved (F) dengan persentase $94 \%$. Pencapaian ini diperoleh dari proses-proses yang sudah 
dijalankan secara maksimal, yaitu: (1) meninjau dan memastikan kesesuaian alur kerja internal organisasi dengan hasil pemanfaatan TI yang diharapkan, (2) melakukan analisis dan evaluasi untuk menentukan persetujuan pendanaan pembangunan sistem informasi berdasarkan keseluruhan portofolio yang sudah dibuat, serta (3) memantau portofolio program, penyediaan dan pemeliharaan layanan dan kemampuan TI dari pihak ketiga berdasarkan kesepakatan yang ada.

Sub domain APO 06, manage budget and costs, berada pada rating scale Fully achieved (F) dengan persentase $92 \%$. Hasil ini menunjukkan pencapaian penuh dari proses pengambilan keputusan yang sudah diterapkan untuk memprioritaskan alokasi sumber dana, serta memastikan alokasi biaya untuk layanan TI dapat diidentifikasi, diukur dan dapat diprediksi untuk mendorong penggunaan sumber daya yang bertanggung jawab termasuk yang disediakan oleh pihak ketiga.

Sub domain APO 07, manage human resources, berada pada rating scale Largely achieved (L) dengan persentase $72 \%$. Hasil ini menunjukkan pencapaian signifikan dari proses pelaksanaan evaluasi kinerja pegawai secara berkala dan tepat waktu, serta ketersediaan sumber daya manusia (SDM) yang memadai untuk mendukung pelaksanaan fungsi pengawasan sistem informasi, dan meminimalkan ketergantungan pada satu individu terkait pengetahuan TI.

Sub domain APO 08, manage relationships, berada pada rating scale Fully achieved (F) dengan persentase $96 \%$. Pencapaian ini menunjukkan bahwa peran, tanggung jawab, dan hubungan dengan pihak ketiga sudah dimaksimalkan dengan komunikasi yang baik.

Sub domain APO 09, manage service agreements, berada pada rating scale Largely achieved (L) dengan persentase 78\%. Hasil ini menunjukkan bahwa proses analisis, diskusi dan kesepakatan semua pihak mengenai kontribusi layanan TI yang disesuaikan dengan portofolio yang ada sudah memperoleh pencapaian yang signifikan.

Sub domain APO 10, manage suppliers, berada pada rating scale Fully achieved (F) dengan persentase 93\%. Proses-proses yang sudah dijalankan secara maksimal berdasarkan hasil pengukuran ini adalah sebagai berikut: (1) menentukan pihak ketiga berdasarkan persyaratan yang ditentukan supaya didapat kecocokan terbaik sesuai dengan kebutuhan organisasi, (2) mengelola hubungan dengan pihak ketiga, (3) memastikan jika ada kontrak yang diubah harus sesuai dengan standar organisasi dan persyaratan hukum, dan (4) secara berkala meninjau keseluruhan kinerja pihak ketiga, termasuk dalam mengatasi masalah yang teridentifikasi selama proses pembangunan sistem informasi berjalan.

Sub domain APO 11, manage quality, berada pada rating scale Fully achieved (F) dengan persentase 96\%. Pencapaian ini diperoleh dari proses-proses yang sudah 
dijalankan secara maksimal, yaitu: (1) menetapkan standar kualitas yang harus dicapai oleh sistem informasi, prosedur dan praktik untuk mendukung tercapainya kualitas yang diharapakan, dan (2) perencanaan pemantauan kualitas layanan sistem informasi secara berkala untuk memantau kepuasan pengguna (user).

Sub domain APO 12, manage risk, berada pada rating scale Largely achieved (L) dengan persentase $83 \%$. Berdasarkan hasil ini, proses pengumpulan data yang relevan untuk melakukan analisis dan identifikasi resiko terkait TI, serta proses dokumentasi dari inventarisasi resiko, sumber daya terkait, kemampuan dan kegiatan pengendalian resiko sudah memperoleh pencapaian yang signifikan.

Sub domain APO 13, manage security, berada pada rating scale Largely achieved (L) dengan persentase $83 \%$. Hasil ini menunjukkan pencapaian signifikan dari proses mengkomunikasikan secara teratur mengenai kebutuhan dan manfaat dari pengamanan informasi yang berkelanjutan untuk mencegah terjadinya ketidaksesuaian informasi yang berulang-ulang.

Berdasarkan penjelasan hasil analisis dan identifikasi temuan dari setiap sub domain, berikut beberapa rekomendasi yang diberikan untuk mengatasi gap capability level menuju level 4 pada sistem informasi E-Legal Drafting Bagian Hukum Setda Kota Salatiga:

(1) Lebih menegaskan dan menyepakati bersama pembagian tugas dan tanggung jawab dari tiap personel struktur organisasi secara jelas, serta memastikan semua personel berperan dalam menjalankan tugasnya.

(2) Membuat prosedur dan konsekuensi yang jelas dan tegas mengenai kepatuhan pengguna dalam mengikuti alur kerja sistem agar fungsi dan tujuan dibangunnya sistem informasi ini dapat benar-benar tercapai.

(3) Pemetaan arsitektur sistem informasi perlu dikaji dengan matang terlebih dahulu sebelum dikomunikasikan dengan pihak ketiga, sebagai contoh siapa saja penggunanya, fungsi apa saja yang ditampilkan pada user interface masingmasing pengguna. Pemetaan yang matang dapat meminimalisir perubahan informasi yang terus-menerus terjadi setiap kali diadakan pertemuan dengan pihak ketiga.

(4) Mendokumentasikan semua aktivitas dan perubahan yang dilakukan pada setiap pertemuan sehingga proses pembangunan sistem informasi dapat berjalan dengan lebih efisien.

(5) Membuat perencanaan evaluasi kinerja secara berkala dan menjalankannya tepat waktu untuk memastikan SDM yang ada sudah cukup mampu mendukung pelaksanaan fungsi pengawasan sistem informasi.

(6) Membuat rencana manajemen resiko yang berkaitan dengan kemampuan pihak ketiga untuk terus memberikan layanan yang aman, efisien dan efektif. 


\section{KESIMPULAN}

Berdasarkan hasil penelitian tentang analisis tata kelola TI menggunakan framework COBIT 5 domain APO (Align, Plan, and Organise) pada sistem informasi E-Legal Drafting Bagian Hukum Setda Kota Salatiga, secara keseluruhan diperoleh nilai capability level saat ini adalah 2,62 yang berada pada level Established process dengan rating scale Fully achieved (87\%). Hasil ini menunjukkan bahwa implementasi tata kelola TI pada sistem informasi E-Legal Drafting sudah diselaraskan, direncanakan dan diatur dengan koordinasi yang baik, yang ditunjukkan dengan adanya bukti pendekatan yang lengkap dan sistematis, serta pencapaian penuh dari proses yang dinilai. Bagian Hukum Setda Kota Salatiga masih memiliki gap sebesar 1,38 untuk mencapai target capability yang diharapkan yaitu pada level 4 (Predictable process). Oleh karena itu, diberikan beberapa rekomendasi yang diharapkan dapat membantu memaksimalkan proses-proses dalam tata kelola sistem informasi E-Legal Drafting agar dapat mencapai target capability yang diharapkan oleh Bagian Hukum Setda Kota Salatiga. Kemudian, hal yang dapat dilanjutkan dan dikembangkan dari penelitian ini adalah analisis tata kelola TI ketika sistem informasi E-Legal Drafting ini sudah digunakan dalam jangka waktu tertentu. Analisis dapat menggunakan domain DSS (Delivey, Service and Support) dalam framework COBIT 5 yang berfokus pada penilaian penyampaian, layanan dan dukungan TI yang aktual bagi organisasi, termasuk manajemen data dan proteksi informasi yang berhubungan dengan proses bisnis organisasi. Hasil analisis ini dapat digunakan sebagai bahan evaluasi apabila akan dilakukan pengembangan sistem di kemudian hari.

\section{DAFTAR PUSTAKA}

[1] R. K. Candra, I. Atastina dan Y. Firdaus, "Audit Teknologi Informasi menggunakan Framework COBIT 5 Pada Domain DSS (Delivery, Service, and Support) (Studi Kasus : iGracias Telkom University)," e-Proceeding of Engineering, vol. 02, no. 01, pp. 1129-1144, 2015.

[2] G. Waluyan dan A. D. Manuputty, "Evaluasi Kinerja Tata Kelola TI Terhadap Penerapan Sistem Informasi Starclick Framework COBIT 5 (Studi Kasus: PT. Telekomunikasi Indonesia, Tbk Semarang)," Jurnal Nasional Teknologi dan Sistem Informasi (TEKNOSI), vol. 02, no. 03, pp. 157-166, 2016.

[3] M. . N. Adolong dan R. Mokodongan, "IMPLEMENTASI TATA KELOLA TEKNOLOGI INFORMASI MENGGUNAKAN FRAMEWORK COBIT 5 DI BPMPTSP BONE BOLANGO," Jurnal Masyarakat Telematika dan Informasi, vol. 08, no. 02, pp. 109-126, 2017. 
[4] R. Sarno, "Audit Sistem dan Teknologi Informasi", Surabaya: ITS Press, 2009.

[5] ISACA, A Business Framework for the Governance and Management of Enterprise IT, Rolling Meadows: ISACA, 2012.

[6] J. Soejanto, S. dan . A. R. Perdanakusuma, "Evaluasi Tata Kelola Teknologi Informasi pada PT. Aerofood Indonesia Bandar Udara Soekarno Hatta Cengkareng dengan Menggunakan Framework COBIT Versi 5.0," Jurnal Pengembangan Teknologi Informasi dan Ilmu Komputer, vol. 02, no. 11, pp. 47144721, 2018.

[7] ISACA, Process Assessment Model (PAM): Using COBIT® 5, Rolling Meadows: ISACA, 2013.

[8] F. Adikara , "IMPLEMENTASI TATA KELOLA TEKNOLOGI INFORMASI PERGURUAN TINGGI BERDASARKAN COBIT 5 PADA LABORATORIUM REKAYASA PERANGKAT LUNAK UNIVERSITAS ESA UNGGUL," dalam Seminar Nasional Sistem Informasi Indonesia (SESINDO), 2013.

[9] F. Ajismanto , "Analisis Domain Proses COBIT Framework 5 Pada Sistem Informasi Worksheet (Studi Kasus: Perguruan Tinggi STMIK, Politeknik Palcomtech)," Cogito Smart Journal, vol. 03, no. 02, pp. 207-221, 2017.

[10] S. I. Farida, F. dan . E. Rahajeng, "USULAN MODEL TATA KELOLA TEKNOLOGI INFORMASI PADA DOMAIN MONITOR, EVALUATE AND ASSESS DENGAN METODE FRAMEWORK COBIT 5," Studi Informatika: Jurnal Sistem Informasi, vol. 07, no. 02, pp. 1-10, 2014.

[11] S. Gondodiyoto, "Audit Sistem Informasi + Pendekatan CobIT", Jakarta: Mitra Wacana Media, 2007.

[12] A. Gunawan dan J. F. Andry, "Audit Aplikasi Zahir di PT Radisa Mahardi Rekatama Menggunakan Framework COBIT 5," dalam Seminar Nasional TEKNOKA, 2017.

[13] H. Hilmawan, O. D. Nurhayati dan I. P. Windasari, “Analisis Tata Kelola Teknologi Informasi menggunakan Kerangka Kerja COBIT 5 pada AMIK JTC Semarang," Jurnal Teknologi dan Sistem Komputer (JTsiskom), vol. 03, no. 02, pp. 247-252, 2015.

[14] T. Oktarina, "TATA KELOLA TEKNOLOGI INFORMASI DENGAN 
Journal of Information Systems and Informatics

Vol. 1, No. 2, September 2019

p-ISSN: 2656-5935 http://journal-isi.org/index.php/isi

e-ISSN: 2656-4882

COBIT 5," Jurnal Informatika, vol. 03, no. 02, pp. 30-38, 2017.

[15] A. P. Utomo dan N. Mariana, "Analisis Tata Kelola Teknologi Informasi (IT Governance) pada Bidang Akademik dengan Cobit Framework Studi Kasus pada Universitas Stikubank Semarang," Jurnal Teknologi Informasi DINAMIK, vol. 16, no. 02, pp. 139-149, 2011. 